\title{
'The State of the World's Children'
}

The first paragraph of the 1985 State of the World's Children* claims that the lives of half a million children were saved in 1984 thanks to the use of oral rehydration, and yet only around $15 \%$ of the world's children have access to the use of this simple method of managing dehydration after diarrhoea.

We in the universities and the National Health Service, have suffered retrenchment and cut backs. These problems are small, however, compared with those facing the children of our world who have been going through dark times in this period of recession. For example, a report from the Catholic Relief Services, which run clinics across Ghana, shows that the proportion of children attending for weighing who are underweight, has increased each year from 1980 and was around $48 \%$ in 1983 compared with $34 \%$ in 1980 .

In the State of the World's Children 1985, the United Nations International Children's Emergency Fund (UNICEF) develops and reports on a strategy for children designed within the limits set by the world wide economic recession.

\section{A child survival and development revolution}

UNICEF has developed a new weapon to bring about this revolution. In one term, this is effective 'advocacy for children'. They have defined priorities and these can be remembered under the acronym GOBI-FFF. The first four letters stand for four activities which can currently be made available to children, even with the present cut backs. The priorities are mentioned briefly here, but not in the same order as letters of the acronym.

Oral Rehydration. In 1984 around 170 million packages of oral rehydration salts were distributed. There is also great interest in newer developments, particularly the preparation of sugar and salt solutions in the home and the use of cereals to replace the glucose, which may have advantages in reducing the stool volume and amount of vomiting.

Immunisation. Here advocacy has been particularly successful. We can learn so much from South
America. Brazil, over more than a decade, had been making immunisation against poliomyelitis widely available, with little success. In 1980 they started a national two day campaign for mass vaccination of all small children. Since then paralytic poliomyelitis has almost disappeared. In 1983 they included measles vaccine on the two vaccination days in the year, giving a total of two and a half million doses. Estimates suggest that this will have saved the lives of 50000 children. This development has been brought about by the skilled use of the media, with involvement of the head of the state, political parties, the church, and any other organisations and groups who will cooperate.

Breast feeding. UNICEF with the World Health Organisation has done much to bring in the code of practice and now see that it is adhered to.

Growth charts. This is a different issue to the others, and while paediatricians who have cared for children in less developed countries are convinced of the value of growth charts, it is difficult to prove this. There are also problems in the understanding and use of charts by those with limited education.

The three Fs. Research around the world has clearly shown that female literacy correlates better with a falling infant mortality rate than any other change in a society. Perhaps the success of Sri Lanka in reducing its infant mortality was laid in the 20 s, when a decision to have universal primary school education was taken. The second ' $F$ ' is for family planning, which is now usually emphasised in terms of adequate child spacing. The final ' $F$ ' is both difficult and controversial as it is food supplementation of pregnant mothers and young children.

\section{Outstanding advances}

The second part of the State of the World's Children is given over to important advances for children in the less developed countries of the world. These are frequently, at first sight, of relatively little importance to children in the West although they may have

*Published by UNICEF, available from TALC, PO Box 49, St Albans, Herts, UK at a cost of $£ 3.00$. 
long term significance. In the 1983 report, the Columbian experience of nursing low birthweight babies and skin contact between the breasts of the mother was described. This has created interest and some controversy. Again advocacy was successful and a doctor and nurse from the Hammersmith Hospital visited the unit and were the lead story in the colour supplement of the London Sunday Times of December 16, 1984. Copies of this supplement have been sent to every medical school in the developing world.

Among the other findings, perhaps that of great interest is a study of measles in the Gambia. This showed that $10 \%$ of the children suffering from this disease died in the subsequent nine months, compared with only $1 \%$ in controls (see Figure).

In the next year's issue we are likely to see the classic paper from New Delhi showing the success of untreated breast milk compared with a control group who received pasteurised breast milk and formula. ${ }^{1}$

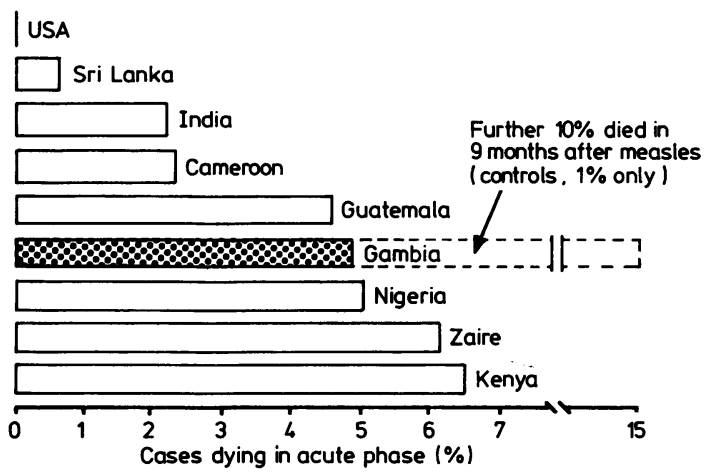

Figure The mortality in the 9 months succeeding severe measles may exceed that during the acute phase of the disease.

\section{Relevant statistics}

The final section of the State of the World's Children is given over to statistics as accurate as can be estimated for countries in the developing world. These are of increasing importance and politicians in developing countries are becoming aware of infant mortality rates as well as other statistics and their significance.

\section{The world's children and British paediatricians}

Four out of five of the world's children live in the developing world. Many paediatricians and others trying to care for these children, if they look for guidance and help, will look to the United Kingdom. Through study of this volume, paediatricians may be better prepared to offer help both to them and to students who come to study paediatrics in the UK.

For those involved in research a study of this volume would be well worthwhile. Many of the problems that face children in the Third World, are not that different from those on which research is being undertaken in this country. Through this book, researchers may see how relatively small changes in research design can be of assistance to the large number of underprivileged children in the less developed countries of our world so badly in need of help from all sides.

\section{References \\ ${ }^{1}$ Narayanan I, Prakash K, Murthy NS, Gujral W. Randomised controlled trial of effect of raw and holder pasteurised human milk and of formula supplements on incidence of neonatal infection. Lancet 1984;ii:1111-3. \\ David MoRLeY Institute of Child Health, 30 Guilford Street, London WC1N 1EH}

